\title{
Concomitant ipsilateral subcapital and intertrochanteric fractures of the femur: a case report
}

\author{
George Loupasis, Panagiotis G Ntagiopoulos, Antonios Asimakopoulos
}

\begin{abstract}
Introduction: We report the case of an unusual combination of concomitant subcapital and intertrochanteric fractures of the hip in a patient after a motorcycle accident. To the best of our knowledge, there is no previous report in the literature of these conditions as a result of high energy trauma or of the treatment used.

Case presentation: A 36-year-old Caucasian man was admitted with this rare fracture combination, and was managed with closed fracture reduction and fixation with a dynamic hip screw combined with an anti-rotational cannulated screw. We found four similar cases on reviewing the literature from 1989 to 2009, but these were reports of older patients after low energy injury.

Conclusion: We found that segmental fracture of the femoral neck region is an extremely rare and uncategorized hip injury that can occur not only in older people but also in young non-osteoporotic patients, and should be considered for inclusion in femoral fracture classification systems.
\end{abstract}

\section{Introduction}

Subcapital femoral fractures secondarily complicating internal fixation of previous united intertrochanteric fractures have been infrequently reported in the literature [1-4]. Simultaneous presentation of ipsilateral neck and intertrochanteric femoral fractures are extremely rare, with only four such cases being reported in the literature during the period 1989 to 2009 [5-8]. All these cases occurred in older patients after a low energy injury.

We report a case of simultaneous ipsilateral subcapital and intertrochanteric fractures in a 36-year old man after a high-energy trauma from a road traffic accident. Based on our clinical experience, the small number of previously published similar cases, the lack of such a fracture pattern in any classification scheme, and a meticulous survey of orthopaedic textbook knowledge, we consider that this is an extremely rare fracture combination, and in terms of patient age, mechanism of injury and the treatment followed, it is to the best of our knowledge, the first such report in the literature.

\footnotetext{
*Correspondence: gloupasis@gmail.com

2nd Orthopaedic Clinic, General Hospital of Athens 'G Gennimatas', Athens, Greece
}

\section{Case presentation}

A 36-year-old and otherwise healthy Caucasian man of Greek extraction was admitted to the hospital after been involved in a road traffic accident. Our patient was riding his motorcycle at an approximate speed of $70 \mathrm{mph}$. He collided head-on with a car, which caused him to be thrown from the motorcycle, landing forcefully on his outstretched left leg.

On physical examination, our patient reported pain in his left hip. He was unable to move his left leg, which was shorter than the right and externally rotated. He had no other injuries. Radiographs of the pelvis revealed an undisplaced Garden II subcapital fracture and a displaced intertrochanteric fracture, with the fracture line originating from the greater trochanter laterally, and ending above the lesser trochanter medially. This pertrochanteric fracture could be classified as type 31-A1.1 according to AO/OTA classification (Figure 1)[9].

Our patient was taken to the theatre the same day. Under C-arm fluoroscopy, the intertrochanteric fracture was accurately reduced by closed means, taking care not to apply excessive traction to avoid iatrogenic displacement of the subcapital fracture. The fractures were fixed with a $135^{\circ}$ dynamic hip screw (DHS) combined with an 


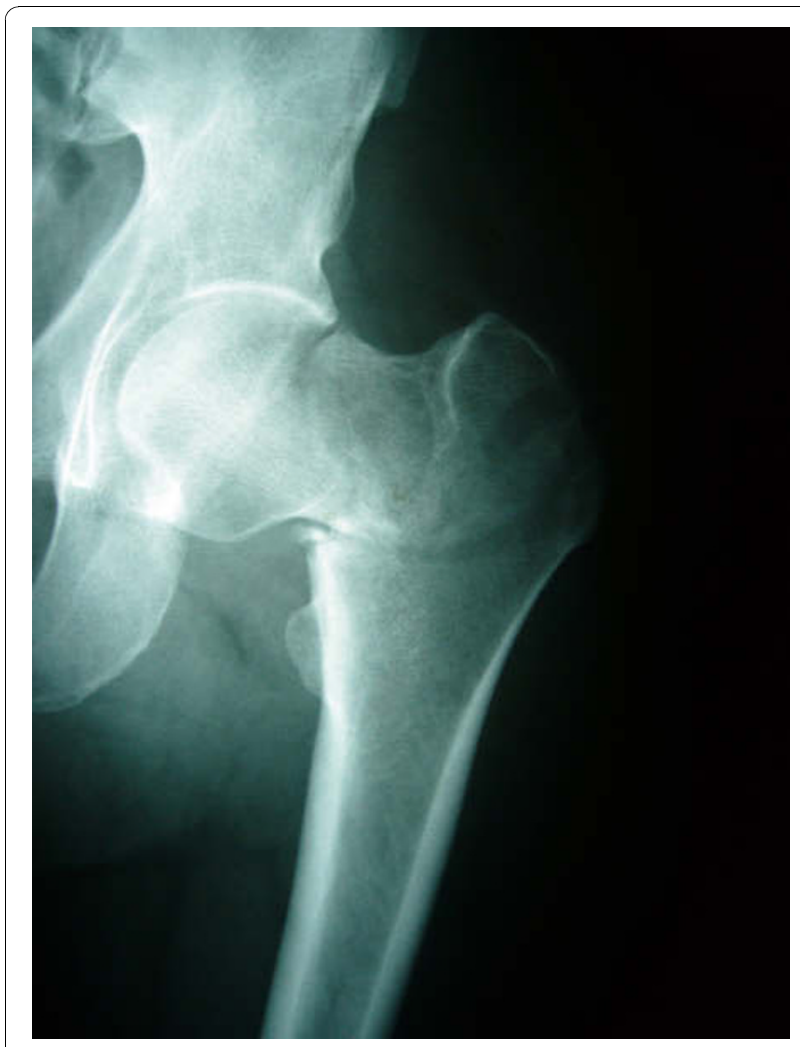

Figure 1 Pertrochanteric fracture combined with subcapital fracture on preoperative anteroposterior radiograph of the left hip.

anti-rotational cannulated screw (Figure 2). To prevent the development of rotational forces to the femoral head during drilling or lag screw insertion, an eccentric temporary guide wire was inserted into the femoral head and the acetabulum before drilling, and removed after the insertion of the lag screw.

Our patient's post-operative rehabilitation protocol included immediate walking with crutches in a touch weight-bearing fashion for eight weeks. Partial to full weight-bearing commenced two months postoperatively. Follow-up included fracture clinic visits at six-month intervals, where the patient was clinically and radiographically assessed and hip functional scores were obtained; Harris hip scores at 12 and 24 months were 88.66 and 93.0, respectively. About one month after the accident, dual energy $\mathrm{X}$-ray absorptiometry was performed at the femoral neck region of the opposite femur, and bone mineral density values were found to be within normal limits. At the last follow-up, two years after the accident, the patient was asymptomatic and had returned to his previous activities, and the fractures were solidly united without evidence of avascular necrosis in the radiographs (Figure 3).

\section{Discussion}

Neck and intertrochanteric fractures of the proximal femur occur predominantly after low-energy trauma in older patients with osteoporosis. The same type of fracture in young patients is usually associated with highenergy trauma.

Although these injuries are one of the most common causes of admission, mainly of older people, to orthopaedic departments, simultaneous occurrence of these fractures on the same side is an extremely rare situation, and only four cases have been reported previously in the literature [5-8]. All four cases concerned older patients who had sustained this unusual combination of fractures after a simple fall. In three of the four cases, the subcapital fracture was either not displaced or only slightly displaced, and the intertrochanteric fracture was displaced but could be classified as a stable injury ( $\mathrm{AO} /$ OTA 31-A1) [6-8]. All four cases were managed either with closed reduction and osteosynthesis with DHS fixation combined with a cannulated screw, or with DHS fixation alone, with a good final result. In the fourth case, there was a combination of a comminuted intertrochanteric and displaced subcapital fracture, which was treated with a bipolar hemiarthroplasty and cerclage wires with a satisfactory outcome [5].

Our case is of interest because of the occurrence of such unusual combinations of fractures in a younger adult without osteoporosis occurring after high-energy trauma, a contrast to the previously reported cases, which have occurred in patients with osteoporosis. Full preservation of the femoral head should be the main goal of treatment of this complex injury in younger patients. Fixation with DHS supplemented with an antirotational cannulated screw should achieve this.

The healing process of the subcapital component of this complex fracture should not be expected to differ from that of an isolated femoral neck fracture. Both fracture lines in our case had an unusual pattern, indicating a different mechanism of injury from that of isolated subcapital or intertrochanteric fracture. Although we can only speculate as to the mechanism of this rare injury, it is likely that the subcapital fracture occurs first when the femoral neck impinges against the acetabulum as a result of an excessive flexion/external rotatory force to the hip. At this stage, if the forces are still not dissipated, a fracture in the intertrochanteric region can occur.

There have been some sporadic reports in the literature about non-concomitant combinations of both fracture types: a primary healed intertrochanteric fracture treated by various methods of fixation, with re-fracturing of the same hip through the femoral neck some time later [1-4]. Several theories have been postulated 


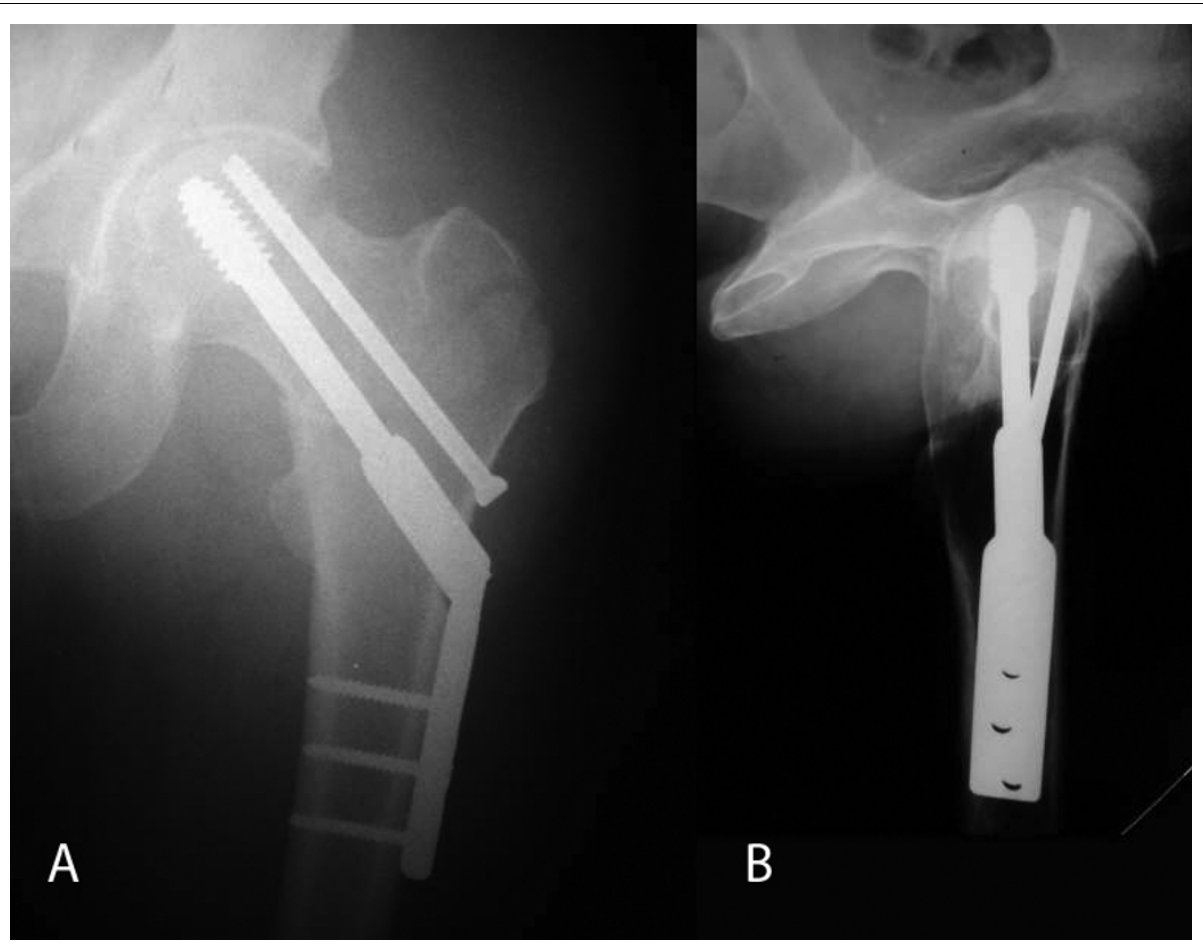

Figure 2 A) Anteroposterior and B) lateral radiographs of the left hip taken immediately after surgery

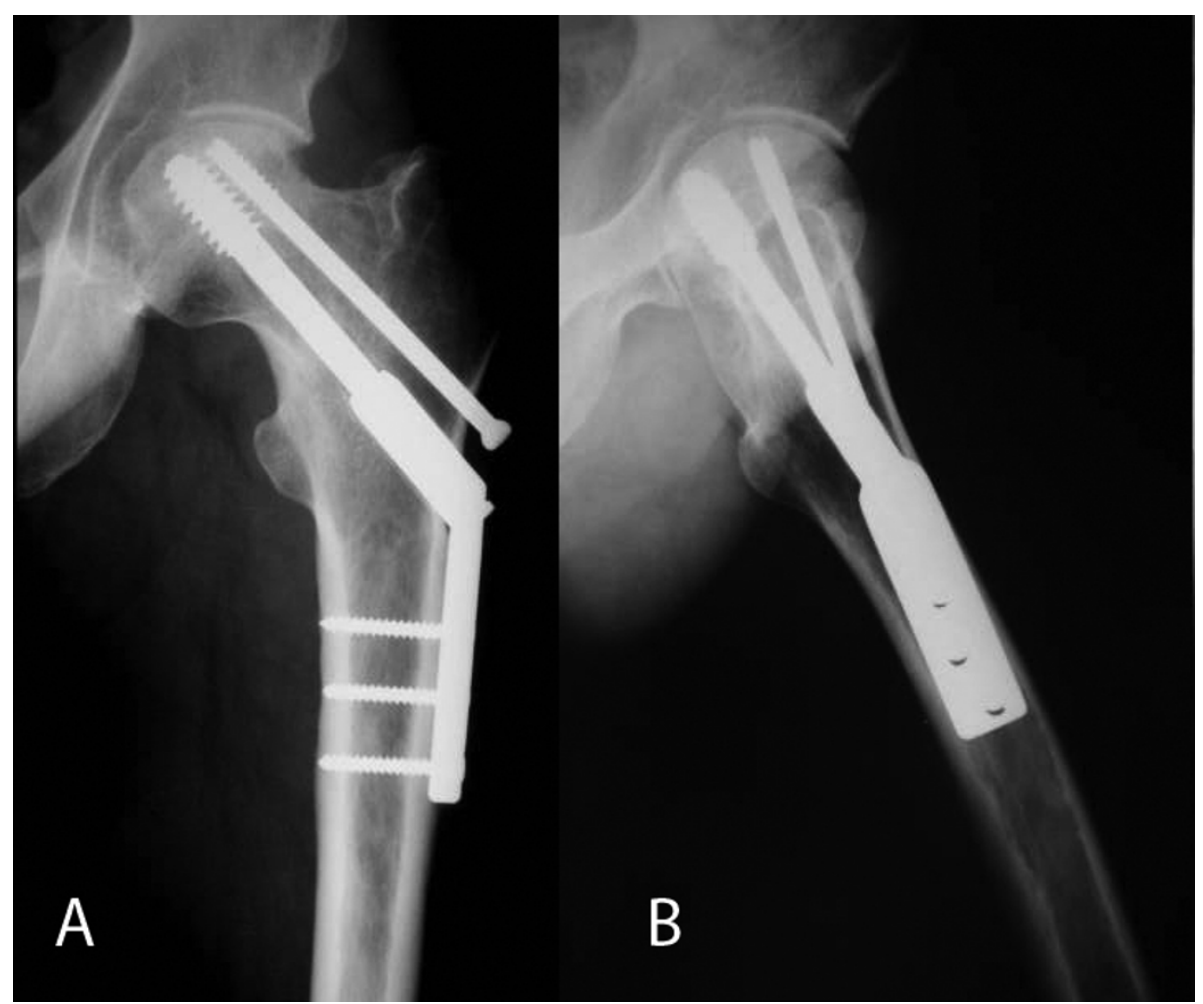

Figure 3 A) Anteroposterior and B) lateral radiographs of the hip taken two years after the operation. 
by various authors regarding the pathogenesis of this fracture pattern, such as inadequate implant fixation[4], imperfect reduction of the primary intertrochanteric fracture [2], and stress protection by the fixation device resulting in local osteoporosis $[1,3]$.

\section{Conclusion}

This report shows that segmental fracture of the femoral neck region is an extremely rare hip injury and can occur not only in the older person but also in younger patients without osteoporosis. Head-preserving and fixation methods should be attempted at all costs despite the combination of two fractures and the great possibility of vascular compromise, and a head-replacing method in a younger patient should be avoided. This unusual complex hip injury has not been previously categorized. Consideration should be given to its inclusion in femoral fracture classification systems.

\section{Consent}

Written informed consent was obtained from the patient for publication of this case report and accompanying images. A copy of the written consent is available for review by the Editor-in-Chief of this journal.

\section{Authors' contributions}

GL, PGN and AA were the operating surgeons. GL and PGN collected the data and prepared the manuscript. All authors read and approved the final manuscript.

\section{Competing interests}

The authors declare that they have no competing interests.

Received: 21 April 2010 Accepted: 15 November 2010

Published: 15 November 2010

\section{References}

1. Cameron HU, Pilliar RM, Hastings DE, Fornasier VL: latrogenic subcapital fracture of the hip: a new complication of intertrochanteric fractures. Clin Orthop Relat Res 1975:218-220.

2. Hardy D, Lafontaine M, Stelmaszyk J, Delince P: [Subcapital fracture of the femoral neck. A rare complication of a pertrochanteric fracture healed in coxa vara position]. Acta Orthop Belg 1990, 56:507-511.

3. Taylor PR, Hepple S, Stanley D: Combination subcapital and intertrochanteric fractures of the femoral neck. Injury 1996, 27:68-71.

4. Wilson-MacDonald J: Subcapital fracture complicating an intertrochanteric fracture. Clin Orthop Relat Res 1985:147-150.

5. An HS, Wojcieszek JM, Cooke RF, Limbird R, Jackson WT: Simultaneous ipsilateral intertrochanteric and subcapital fracture of the hip. A case report. Orthopedics 1989, 12:721-723.

6. Cohen I, Rzetelny V: Simultaneous ipsilateral pertrochanteric and subcapital fractures. Orthopedics 1999, 22:535-536.

7. Isaacs C, Lawrence B: Concomitant ipsilateral intertrochanteric and subcapital fracture of the hip. J Orthop Trauma 1993, 7:146-148.

8. Pemberton DJ, Kriebich DN, Moran CG: Segmental fracture of the neck of the femur. Injury 1989, 20:306-307.

9. Fracture and dislocation compendium. Orthopaedic Trauma Association Committee for Coding and Classification. J Orthop Trauma 1996, 10(Suppl 1):1-154, v-ix. doi:10.1186/1752-1947-4-363

Cite this article as: Loupasis et al:: Concomitant ipsilateral subcapital and intertrochanteric fractures of the femur: a case report. Journal of Medical Case Reports 2010 4:363.

\section{Submit your next manuscript to BioMed Central} and take full advantage of:

- Convenient online submission

- Thorough peer review

- No space constraints or color figure charges

- Immediate publication on acceptance

- Inclusion in PubMed, CAS, Scopus and Google Scholar

- Research which is freely available for redistribution

Submit your manuscript at www.biomedcentral.com/submit 